\title{
Estudo fenomenológico sobre a vivência da morte em uma unidade de terapia intensiva neonatal
}

Phenomenologic study about experiences when living the death in the neonatal critical care unit Estudio fenomenológico sobre la vivencia de la muerte en la unidad de terapía intensiva neonatal

\section{Laureana Cartaxo Salgado Pereira Silva', Cecília Nogueira Valença', Raimunda Medeiros Germano'}

'Universidade Federal do Rio Grande do Norte. Departamento de Enfermagem. Natal, RN

Submissão: 28/07/2009

Aprovação: 14/08/2010

\section{RESUMO}

Esta investigação teve como objetivos: descrever a vivência de cuidado de profissionais de enfermagem de unidade de terapia intensiva neonatal diante da morte e compreender os sentimentos diante da morte do recém-nascido. Pesquisa Qualitativa com abordagem fenomenológica, tendo como pergunta norteadora: Como você se sente diante da morte do recém-nascido na UTI onde trabalha? Participaram da entrevista 12 enfermeiros e técnicos de enfermagem da UTI. Emergiram sentimentos como culpa, fracasso e negação. Compreendendo o fenômeno estudado, afirmamos Que a morte do recém-nascido no espaço da UTI é uma vivência de sentimentos conflituosos, por vezes dolorosos para os profissionais de enfermagem.

Descritores: Enfermagem; Morte; Unidade de terapia intensiva; Sentimentos.

\section{ABSTRACT}

This research aimed at describing the care experiences of neonatal critical care nurses when facing the death and to understand their fellings before the death of the newborn. Qualitative research with a phenomenological approach, with the guiding Question: How do you feel about the death of the newborn ICU where you work? Attended the interview 12 nurses and ICU nursing. Emerging feelings such as guilt, failure and denial. Understanding the phenomenon being studied, we affirm that the death of the newborn within the ICU is an experience of conflicting feelings, sometimes painful for the nurses.

Key words: Nursing; Death; Intensive care unit; Feelings.

\section{RESUMEN}

Esta investigación tuvo como objetivo describir la experiencia de la atención de las enfermeras de la unidad neonatal de cuidados intensivos antes de la muerte y comprender los sentimientos antes de la muerte del recién nacido. Investigación cualitativa con abordaje fenomenológico, con la pregunta orientadora: ¿Cómo te sientes acerca de la muerte de los recién nacidos en la UCI donde usted trabaja? Asistió a la entrevista 12 enfermeras y la enfermería en la UCI. Surgido como sentimientos de culpa, el fracaso y la negación. Entender el fenómeno estudiado, afirmamos que la muerte del recién nacido dentro de la $\mathrm{UCl}$ es una experiencia de sentimientos contradictorios, a veces dolorosas para las enfermeras.

Descriptores: Enfermería; Muerte; Unidad de terapía intensiva; Sentimientos.

\footnotetext{
AUTOR CORRESPONDENTE Cecília Nogueira Valença. Universidade Federal do Rio Grande do Norte. Departamento de Enfermagem.

Av. Senador Salgado Filho, 3000. Lagoa Nova. CEP 59078-970. Natal, RN. E-mail: cecilia_valenca@yahoo.com.br
} 


\section{INTRODUÇÃO}

A morte é um acontecimento inevitável e certo na vida de todo ser vivo. A morte é um evento definitivamente ligado à vida, fazendo, portanto, parte integrante desta ${ }^{(1)}$. Outro aspecto que merece nossa observação é o fato de Que o homem é o único ser vivo possuidor da consciência da morte, seja a do outro ou a sua própria morte. A consciência da morte é um privilégio peculiar ao homem ${ }^{(2)}$.

É sobre essa complexidade Que envolve o tema da morte Que pretendemos dialogar, relacionando-o ao contexto hospitalar, na assistência ao recém-nascido grave, no Que se refere primordialmente aos sentimentos Que vivenciam os profissionais de saúde diante da morte de crianças, em unidades de terapia intensiva neonatal (UTIN). Essa dificuldade acompanha o homem, as famílias, os profissionais da área biomédica, no âmbito hospitalar e também domiciliar.

Assim, na presente investigação, dirigimos a atenção para os profissionais de enfermagem Que lidam diariamente com a morte de recém-nascidos (RN) em UTIN, compondo o objeto de estudo: vivência de cuidado de profissionais de enfermagem em unidade de terapia intensiva neonatal diante da morte do recém-nascido.

Refletindo acerca deste tema, encontramos alguns problemas Que merecem destaque, a saber: dificuldade em dar a notícia de morte aos pais do bebê, inconformação com a morte do paciente Quando as medidas terapêuticas não alcançam êxito, dificuldade em decidir a viabilidade de tratamento para pacientes graves. $\mathrm{E}$ ainda: dificuldade da equipe multiprofissional em lidar com a naturalização do evento morte, sentir a dor do outro e não saber lidar com ela, desconhecer os limites e necessidades como cuidadores. Estes conflitos reiteraram a necessidade em buscar respostas, aprofundando nossos Questionamentos ao realizarmos um estudo Que pudesse contribuir com a equipe de enfermagem e demais profissionais da área da saúde Que trabalham na UTIN, diante das adversidades da vida/morte.

A assistência em terapia intensiva é considerada como uma das mais complexas do sistema de saúde, pois os pacientes mais graves das unidades hospitalares são alocados nas UTI, demandando o uso inevitável de tecnologias avançadas e, especialmente, exigindo pessoal capacitado para tomar decisões rapidamente e adoção imediata de condutas $^{(3)}$. Os cuidadores, neste espaço, são os profissionais de saúde, Que dividem o lugar com os bebês e toda a variedade de equipamentos necessários para o suporte de suas vidas, numa rotina Que se tornou desgastante, com uma variedade de procedimentos complexos a realizar.

Os aspectos assistenciais referentes à humanização em UTI são evidenciados freqüentemente pela mídia, apontando os trabalhadores da saúde como sendo pessoas frias, tecnicistas e, muitas vezes, incapazes de mostrar afeto pelo paciente e/ou família. Ao se tratar de enfermeiras de UTI, essa realidade torna-se mais evidente, levando-se em consideração o ambiente agressivo do espaço de trabalho e o próprio Quadro clínico dos pacientes ${ }^{(4)}$.

Apesar desse pensamento do senso comum de Que o profissional de saúde é estóico, uma profunda emoção acomete aquele que penetra nesse meio violento, portador do conflito vida/morte e Que suscita imagens de grande crueza. É, portanto, necessário Que o trabalhador de unidade de terapia intensiva encontre um espaço onde possa falar dessas emoções para Que, assim, as interações Que se travam neste ambiente, diariamente, sejam menos conflituosas $^{(5)}$.

Portanto, mediante essas Questões polêmicas, Que permeiam o nosso cotidiano hospitalar, e compreendendo a necessidade de melhorar a condição de Quem cuida, bem como a assistência prestada aos recém-nascidos e seus familiares frente à morte, indagamos acerca da vivência e dos sentimentos dos profissionais de enfermagem em UTIN, diante da experiência com a morte de crianças.

Portanto, foram objetivos deste estudo: descrever a vivência de cuidado de profissionais de enfermagem de unidade de terapia intensiva neonatal diante da morte e compreender os sentimentos diante da morte de recém-nascido

Esta investigação é um recorte da dissertação de mestrado intitulada Sentimentos de profissionais de enfermagem diante da morte de recém-nascidos em uma unidade de terapia intensiva, defendida em 2007, no programa de pós-graduação em enfermagem da Universidade Federal do Rio Grande do Norte.

\section{METODOLOGIA}

Tratou-se de um estudo descritivo de abordagem Qualitativa e cunho fenomenológico, objetivando compreender a experiência vivenciada pelos profissionais de enfermagem de uma UTIN, no Que se refere a vivência de cuidado e aos sentimentos diante da morte do recém-nascido.

A compreensão do fenômeno em evidência, levou-nos a escolher um caminho metodológico Que possibilitasse a aproximação das vivências da equipe de enfermagem de UTIN, abarcando o pensar, o sentir e o agir. Desta forma, optamos pela pesquisa Qualitativa, de cunho fenomenológico Que valoriza os significados Que as pessoas atribuem aos seus sentimentos experienciados, e Que se revelam a partir das suas descrições ou discursos. Entendemos Que esta vertente metodológica possibilita uma melhor compreensão acerca da vivência dos profissionais de enfermagem em UTIN, e dos sentimentos que os envolvem diante da morte das crianças.

A investigação teve como cenário a UTIN de dois hospitais públicos do Estado do Rio Grande do Norte, na cidade de Natal, sendo um deles militar. Ambos são unidades de referência para gestantes e recém-nascidos em situação de risco, bem como possuem o título de Hospital Amigo da Criança, conferidos pelo Fundo das Nações Unidas para a Infância (UNICEF). Essas unidades hospitalares foram escolhidas, como espaço de pesquisa, por serem locais onde desenvolvemos nossas atividades profissionais e por serem, sobretudo, serviços de referência na assistência ao recémnascido com risco de vida. Nesses ambientes, os profissionais experimentam cotidianamente a morte de recém-nascidos e nesta vivência buscamos os sentimentos destes profissionais diante da morte destas crianças.

O projeto foi aprovado pelo Comitê de Ética em Pesquisa da Universidade Federal do Rio Grande do Norte (CEP / UFRN), conforme protocolo no 202/06, em 24 de janeiro de 2007.

Os participantes do estudo, sobre a temática em apreço, foram os profissionais que fazem parte da equipe de enfermagem (enfermeiros e técnicos de enfermagem), Que desempenham suas atividades em UTIN. Foram estabelecidos alguns critérios de inclusão para participação deste estudo: ser enfermeiro ou técnico 
de enfermagem; trabalhar, no mínimo por seis meses em UTIN; ter vivenciado a situação de morte de recém-nascido; ter interesse e disponibilidade para participar do estudo.

Participaram do estudo doze profissionais de enfermagem Que desempenham suas atividades profissionais nas UTIN selecionadas para a investigação. Dentre os Quais, seis são enfermeiros e seis técnicos de enfermagem. Esse número de depoentes foi estabelecido no decorrer da etapa de campo. Assim, o critério utilizado para findar a etapa das entrevistas foi a saturação do conteúdo dos discursos. Para preservarmos o anonimato destes, optamos por identificá-los com nomes de estrelas, naturalmente uma representação simbólica e ilustrativa correlacionada ao estudo em pauta.

A produção dos dados foi feita através da técnica da entrevista de natureza fenomenológica, a partir da seguinte Questão: Como você se sente diante da morte do recém-nascido na UTI Que você trabalha? Todos os todos os integrantes da equipe de enfermagem dos dois cenários da investigação foram convidados a participar da pesquisa. Foram informados com relação a: objetivos, importância de sua colaboração para o desenvolvimento da pesquisa, caráter confidencial de suas respostas, fidedignidade com Que os dados seriam trabalhados e o direito de desistir de participar do estudo a Qualquer tempo. Aqueles Que voluntariamente consentiram sua participação e assinaram o TCLE foram incluídos como depoentes na etapa de campo.

As entrevistas foram realizadas no mês de fevereiro de 2007 , de acordo com a disponibilidade dos profissionais, Quanto à data e hora, previamente agendadas. As mesmas foram gravadas, após autorização dos depoentes. Na sequência, foram transcritas e lidas cuidadosamente, a fim de Que nenhuma informação relevante fosse desconsiderada pela pesQuisadora. As informações foram analisadas de acordo com a trajetória fenomenológica ${ }^{(6)}$, Que consiste em três momentos: descrição, redução e a compreensão fenomenológica. Essa forma de registro possibilitou a captação, com fidelidade, do discurso do entrevistado.

A partir da análise dos dados, vislumbramos os principais sentimentos Que envolvem os profissionais diante da morte em UTIN, reunidos em unidades de significado da seguinte maneira: culpa, fracasso e negação. Todos apresentavam uma relação com o fazer, isto é, com a implementação de ações para lidar com a morte. As unidades de significado apreendidas representam perspectivas do fenômeno estudado e refletem como os profissionais da investigação expressam esses sentimentos diante da morte em UTIN, enquanto mergulhados neste contexto.

\section{RESULTADOS E DISCUSSÃO}

O perfil dos participantes do estudo pode ser delineado a partir das seguintes características: oito são do sexo feminino e Quatro do sexo masculino, na faixa etária de 26 a 50 anos; a maioria é casada, sendo três solteiros e um divorciado. Dentre todos, nove têm filhos e três não. A religião prevalente foi a católica; o tempo de formado variou entre três e vinte e cinco anos e o tempo de serviço em UTIN de sete meses a Quinze anos. Com relação a vínculos empregatícios, a maioria é funcionário público e apenas dois trabalham em empresa privada.

Da essência de suas falas, foram identificadas as unidades de significados, as Quais expressaram uma diversidade de sentimentos comumente acompanhados de dor e sofrimento. O esforço de compreensão desta realidade empírica foi alicerçado por autores Que direta ou indiretamente abordam o tema, ou se preocupam com a condição humana. Tais sentimentos foram alinhados em três unidades de significado: Culpa, Fracasso e Negação.

$\mathrm{Na}$ perda do paciente (morte, óbito, seja Qual for sua denominação), é notória a inconformação e insatisfação reveladas nas falas dos depoentes por se sentirem culpados por essas perdas. O preparo para salvar vidas, Que constitui o ideário na formação dos profissionais da saúde, embota, de certa maneira, a concepção de fim, de morte biológica. O empenho se concentrou em salvaguardá-la e pouco em compreender sua finitude. A formação acadêmica fortalece a idéia de profissionais como deuses; assim sendo, são preparados para derrotar a morte, mas Quando ela vence, sentem-se culpados.

Precisamos trabalhar com maiores responsabilidades para evitar esse tipo de acontecimento. (ALIOTH)

Será Que precisou cuidar mais? Será que precisava me envolver mais? Ou o prognóstico dele era a morte? (ALDEBARAN)

No momento Que a criança tá muito ruizinha, fico angustiada: se chega a óbito o sentimento é de decepção, por não ter feito alguma coisa a mais. (BELATRIX)

\section{A gente tenta fazer de tudo. Mas não consegue. (MENKAR)}

Assim sendo, manifestam sentimentos de auto-reprovação, baixa auto-estima e desamparo Que fazem parte do luto. Enfermeiros e técnicos de enfermagem estão em constante desgaste, pelo convívio com a morte, e eles próprios desconhecem esta condição Que lhe é inerente $\mathrm{e}^{(7)}$. Acrescentamos ainda Que essa situação se estende a todos aQueles Que se envolvem com pacientes em condição de risco e vulnerabilidade.

No espaço onde o profissional de enfermagem trabalha, dispensando uma enorme atenção no sentido de desenvolver técnicas para prolongar a vida, como no caso de uma UTI, outros sentimentos emergem, permeando a atmosfera de sua luta laboral, afetiva e emocional ligados a uma impotência desconcertante Que nas falas identificamos como fracasso, frustração, fraqueza e incapacidade.

\section{A morte é um fracasso para toda a equipe. (ALIOTH)}

\section{Você se sente incapacitado, impotente. (SHAULA)}

A impotência de não poder dominar a morte é uma constante nos relatos, remetendo o sujeito, por vezes, ao fenômeno da sua própria morte. Esses sentimentos são mais intensos Quando os profissionais se dão conta Que, apesar da tecnologia, permanecem limitados para eliminar a morte.

Depois que se faz de tudo e ele morre, em parte você morre [...] Tudo que você fez foi por água abaixo. (MENKAR)

Quando a gente não consegue é um momento totalmente triste. 
(POLARIS)

Quando a criança chega a óbito é onde a gente sente. (ALDEBARAN)

Compreendemos o sofrimento e a dificuldade estabelecidos nessa complexa relação de cuidado com o recém-nascido frente à sua morte. O fato de não se alcançar o objetivo de curar o enfermo evidencia um fracasso, por levar à compreensão de que a morte não é mais considerada como o limite natural da vida humana, ou algo inerente à própria existência ${ }^{(8)}$.

Esse aspecto de sentir-se derrotado pela morte advém da cultura ocidental, influenciada pelo capitalismo Que, fazendo apologia ao consumismo, torna a morte inimiga do homem.

Expressões, como não morrer no meu plantão, uma perda inesperada, a morte ninguém gostaria de ver, estar ali para evitar essa morte, não gostar de estar perto Quando ela ocorre, passar o plantão com o recém-nascido vivo, conduzem-nos a várias indagações acerca dessas reações em profissionais de saúde.

A certeza da finitude não parece encontrar espaço no aparato tecnológico Que constitui o mundo de uma UTI. O conhecimento técnico/científico de tal forma vem evoluindo e se sofisticando Que os profissionais são formados para evitar a morte, como se esta não fizesse parte da vida. Em consequência, há uma carência de profissionais preparados para a despedida.

Não parece existir um preparo por parte dos enfermeiros e demais profissionais de saúde no tocante ao paciente terminal. Portanto, essa complexa tarefa Que extrapola a relação direta enfermeiro/ paciente, estendendo-se também à família, exige, atualmente, uma reformulação dos sentimentos de cada profissional sobre a morte e o morrer e, até mesmo, a respeito da própria vida ${ }^{(9)}$.

Assim, podemos compreender os Questionamentos: Por Que considerar inesperada a morte Que pode acontecer? Por Que não se gosta de ver a morte, Quando se tem Que assistir a esse paciente? Por Que não morrer no meu plantão, Quando no processo de trabalho da enfermagem o cuidado com o moribundo é uma das atribuições dessa equipe? Por Que ter Que passar o plantão com o recém-nascido vivo, Quando de fato ele pode morrer?

A negação deste fenômeno, nas falas, se faz presente de forma marcante e explícita, principalmente, Quando as evidências sinalizam para o momento da partida, da perda, da dor e Que não Queremos: o morrer.

\section{Tomara que esse bebê não venha a óbito. (ALDEBARAN)}

\section{É uma parte Que ninguém gostaria de ver. (POLARIS)}

Eu não gosto de estar nem perto, Quando acontece essa coisa [referindo-se à morte]. (CAPELLA)

Os profissionais de saúde referem não aceitar a morte, buscando várias maneiras de ocultá-la, inclusive substituindo a palavra morte por diversos sinônimos, como falecimento, óbito, alta celestial, entre outros ${ }^{(7)}$.

Fico feliz Quando não morre no meu plantão. (BELATRIX)

Quando não morre no meu plantão penso Que fiz alguma coisa para prorrogar isso.(BELATRIX)

Estes relatos evidenciam a não aceitação da morte por parte dos profissionais. Negar é uma forma de não entrar em contato com as experiências dolorosas, e, deste modo, permite-se que se viva, onde existe a ilusão da imortalidade ${ }^{(10)}$.

\section{Uma perda inesperada. (ALIOTH)}

É importante Que você passe o plantão com o menino vivo. (MENKAR)

Compreende-se Que os profissionais de saúde têm enorme dificuldade em aceitar seus próprios limites, utilizando-se de mecanismos de defesa para negar um acontecimento natural e inevitável da vida, Que é a morte ${ }^{(1)}$.

Todos esses sentimentos Que emergem da subjetividade dos profissionais de enfermagem são inerentes ao ser humano, refletindo seu encontro com a sua humanidade.

\section{CONCLUSÃO}

Estudar sobre a morte nos fez compreender Que pouco conhecemos sobre a vida/morte Que enfrentamos diariamente. No entanto, a tanatologia ainda encontra-se restrita a alguns grupos específicos e outros curiosos, Quando deveria ser difundida entre cientistas da área, estudantes, profissionais de saúde, religiosos, educadores, enfim, entre todas as pessoas, pelo fato de tratar de algo Que é intrínseco no ser humano: sua finitude.

Considerando ser a morte parte da vida, faz-se necessário a realização de outras pesquisas Que contribuam com essa área do conhecimento, no Que diz respeito às condições dos profissionais de áreas especializadas que lidam diariamente com a finitude, como no cenário da UTI neonatal. Esse espaço por si só já é dotado de uma complexidade no manejo das condições clínicas, em geral bastante comprometidas, dos pacientes, exigindo do profissional de saúde um padrão de excelência no domínio de conhecimentos e habilidades específicos, por vezes, negando sua subjetividade.

Identificamos Que a vivência cotidiana dos profissionais de enfermagem em UTI neonatal não era suficiente para prepará-los para a morte de um recém-nascido, visto Que afloraram sentimentos como culpa, fracasso e negação da morte, representando dificuldade em lidar com a transição vida-morte diante de um ser cuja vida está acabada, sendo Que ela apenas começara.

Assim sendo, o desgaste numa luta laboral e tecnológica incessante contra a morte nem sempre surtirá efeito no prolongamento da vida do recém-nascido, devendo a equipe de saúde estar preparada bem como preparar os familiares da criança para seu possível, inevitável e iminente falecimento. Essa postura é dotada de grande complexidade por demandar uma re-significação acerca da morte, do morrer e da existência.

Percebemos ser fundamental a compreensão da cada morte de cada ser humano como sendo um acontecimento único, não devendo o profissional de enfermagem assumir uma postura de não-aceitação ou inconformismo com a sua ocorrência a cada vez Que ela acontecer, mas de perceber esse fenômeno como integrante íntimo e intrínseco do ciclo de vida do recém-nascido. 


\section{REFERÊNCIAS}

I. D'Assumpção EA. Tanatologia - Ciência da vida e da morte. In: Anais do I Congresso Brasileiro de Tanatologia e Bioética; 2003 abr 24-26; Belo Horizonte (MG), Brasil. Belo Horizonte: SOTAMIG; 2003. p. 21-38.

2. Ikeda D. Vida, um enigma, uma jóia preciosa. $5^{\mathrm{a}}$ ed. Rio de Janeiro: Record; 2003.

3. Inoue KC, Matsuda LM, Silva DMPP, Uchimura TT, Mathias TAF. Absenteísmo-doença da equipe de enfermagem em unidade de terapia intensiva. Rev Bras Enferm 2008; 6I (2): 209-I4.

4. Santana N, Fernandes JD. O processo de capacitação profissional do enfermeiro intensivista. Rev Bras Enferm 2008; 6 I (6): 809 15.

5. Ministério da Saúde (BR). Atenção humanizada ao recémnascido de baixo peso: método mãe-canguru: manual do curso. Brasília: Ministério da Saúde; 2002.
6. Martins I, Bicudo MAV. A pesquisa Qualitativa em psicologia. $3^{\text {a }}$ ed. São Paulo: Centauro, 2003.

7. Zorzo ICC. O processo de morte e morrer da criança e do adolescente: vivência dos profissionais de enfermagem [dissertação]. Ribeirão Preto: Escola de Enfermagem de Ribeirão Preto, Universidade de São Paulo; 2004.

8. Poles K, Bousso RS. Compartilhando o processo de morte com a família: a experiência da enfermeira na UTI pediátrica. Rev Latino-am Enfermagem 2006; 12(2): 207-13.

9. Germano RM. A ética e o ensino da ética na enfermagem do Brasil. São Paulo: Cortez; 1993.

10. Cassorla RMS. “Da morte”. São Paulo: Papirus; 1991.

1 1. Oba MDV, Tavares MSG, Oliveira MHT. A morte mediante as representações sociais dos profissionais de saúde. Rev Bras Enferm 2002; 55(1):26-30. 